\title{
The relevance of ultrasound examination of the foot and ankle in patients with rheumatoid arthritis - a review of the literature
}

\author{
Oana Șerban, Maria Bădărînză, Daniela Fodor
}

$2^{\text {nd }}$ Internal Medicine Department, "Iuliu Hațieganu” University of Medicine and Pharmacy, Cluj-Napoca, Romania

\begin{abstract}
Rheumatoid arthritis (RA) is an inflammatory disease characterized by symmetrical involvement of the joints and tendons, especially of the hands and wrists, but also of the feet and ankles from the very beginning of the disease. For the patient, the foot and ankle involvement is equally important as the other joints, since it affects the functionality of the feet and the quality of life of the patients. It is already known that subclinical involvement of the ankles and feet occurs even in patients that are considered in clinical remission, thus they do not need for changes of therapy, but still might benefit from it. In spite of this, the clinicians do not give enough care to the ankle and foot in RA patients, especially if asymptomatic, resulting future deformities, joint damage and feet disability. In order to show the importance of the feet and ankles in RA patients and to demonstrate the indispensable role of ultrasonography (US) for that purpose, at the same time displaying the US abnormalities that should draw our attention, we performed this review of the literature.
\end{abstract}

Keywords: ultrasound; synovitis; foot; ankle; rheumatoid arthritis

\section{Introduction}

The involvement of the ankle and foot in rheumatoid arthritis (RA) patients is frequently reported, even from the early stages of the disease. However, rheumatologists give less attention to the foot and ankle joints in comparison to other joints, especially those of the hand and wrist. Furthermore, currently most used disease activity measuring tools, such as the Simplified Disease Activity Score (SDAI) and Disease Activity Score in 28 joints (DAS28), do not take into consideration the foot and ankle, since it has been demonstrated that adding these joints to the

Received 04.03.2019 Accepted 29.03.2019

Med Ultrason

2019, Vol. 21, No 2, 175-182

Corresponding author: Daniela Fodor, MD, PhD

2-4 Clinicilor street, 400006, Cluj Napoca, Romania

E-mail: dfodor@umfcluj.ro 28-joints count do not influence significantly the evaluation of disease activity [1]. Recently, on a relatively large cohort of patients with early RA it has been found that the omission of foot joints from the disease activity measuring tools underestimated the disease activity, since many patients considered in remission had ultrasound (US)detectable foot synovitis which is predictive for disease relapse, damage progression and functional impairment [2].

Feet and ankles joints inflammation leads to joint damage and deformities resulting in increased forefoot pressure, foot disability and pain (initially noticed at the level of the forefoot joints), that ultimately affect patients' daily activities and mobility [3]. Thereby, RA patients often have difficulties in finding appropriate footwear or walking and would benefit from proper foot care given by the rheumatologist or the podiatrist [4]. Subclinical involvement of the feet and ankles joints (with the aspect of synovitis in US examination), frequently overlooked 
by clinicians, also impairs feet functionality and patients' quality of life [5]. Foot and ankle disability and pain in RA patients significantly improve after initiation of biological therapy [6] but this is valuable if the treatment is initiated before the advance/irreversible lesions appeared.

It is already known that US-detectable synovitis predicts better the joint damage progression than clinical tenderness [7]. Also, the presence of US erosions and PD positive synovitis in patients with early arthritis (including RA) is predictive for subsequent radiographic damage $[8,9]$. The utilization of US in patients presenting with inflammatory arthritis classified as RA by a rheumatologist, has significantly increased the diagnosis certainty [10]. Compared to magnetic resonance imaging (MRI), US is equally sensitive in the detection of synovitis and superior in the detection of tenosynovitis, but is inferior in the detection of bone erosions in the small joints of the hand and foot [11].

The aim of this review is to analyse the published papers regarding foot and ankles abnormalities detectable by US in RA patients and to evaluate their importance and frequencies, together with the contribution of US in the complete evaluation of RA patients.

\section{Ultrasound findings of the forefoot}

\section{Metatarsophalangeal (MTP) joints synovial hypertrophy and effusion}

When searching for synovial hypertrophy in the MTP joints, the utility of US is comparable with MRI, the agreement between these two being good. However, US has been found to be more effective than MRI in the detection of joint effusion, being a real time examination that allows compression and dislocation of fluid [12]. The concordance between US and clinical examination is poor at the level of MTP joints of RA patients, US being very useful in the identification of synovitis even in patients without clinical findings [13].

US detectable MTP joints synovitis (synovial hypertrophy and PD signal) is significantly more frequent in RA patients even in asymptomatic feet of healthy individuals [14]. Scire et al [15] found significantly higher synovial hypertrophy, effusion and PD signal scores in RA patients than patients with undifferentiated arthritis, spondylarthritis (SpA), connective tissue diseases, crystal-associated arthritis and non-inflammatory arthropathies. The most prevalent sites for synovial hypertrophy and effusion in the forefoot of RA patients were 2nd to 4th MTP joints, but PD signal (suggestive for active synovitis) was most commonly observed in the 5th MTP, possibly explaining the predilection for joint damage at this level.
Moreover, in RA patients in clinical remission, PD signal (indicating subclinical synovitis) was identified in their MTP joints even in the absence of hand and wrist involvement [16], thus indicating the utility of feet US and the necessity of targeting US remission (no synovial hypertrophy and no PD signal).

Since the forefoot joints are exposed to an important amount of mechanical stress during standing, walking or other physical activities, including sports, the MTP joints have US abnormalities even in healthy individuals $[17,18]$. Some authors referred to these US findings as normal/abnormal low-echoic synovial areas [17], and others as synovial hypertrophy (SH) [18] and/or effusion [19].

Hiraga et al [17] performed a study on asymptomatic healthy patients and found a low-echoic synovial area in the dorsal aspect of all MTP joints (from $1^{\text {st }}$ to $5^{\text {th }}$ ) of all the subjects assessed. These US findings were the largest in the $1^{\text {st }}$ and $2^{\text {nd }}$ MTP and decreased toward the $5^{\text {th }}$ MTP. The authors did not evaluate the presence of the PD signal.

Keen et al [18] in a study performed on subjects with $1^{\text {st }}$ MTP joint pain and asymptomatic controls, found that low-grade synovitis was present at the level of the $1^{\text {st }}$ MTP in both symptomatic and asymptomatic individuals. The presence of synovitis was most commonly associated with the presence of osteophytes in the symptomatic subjects, but low-grade PD signal was present only in a small amount of the symptomatic volunteers.

Luukkainen et al [19] searched for effusion in MTP and tibio-talar (TT) joints in healthy asymptomatic individuals and found 3.8\% of the assessed MTP joint (18\% of the persons) with effusion, respectively $4 \%$ of the TT joints ( $6 \%$ of the persons). No subject with both MTP and TT effusion was identified and PD signal was not found in any joint assessed.

Machado et al [20] assessed healthy adults for US changes in multiple joints, including the forefoot, and identified high-grade synovial hypertrophy most frequently in $1^{\text {st }}$ and $2^{\text {nd }}$ MTP $(69.3 \%, 78.8 \%$ respectively), having also a PD signal, especially in the $1^{\text {st }}$ MTP $(15.8 \%)$.

Micu et al [21] evaluated multiple joints in pregnant and non-pregnant young women and found gray scale inflammatory-like findings (mostly low-grade) in $44.4 \%$ of the $1^{\text {st }}$ to $5^{\text {th }}$ MTP joints of healthy young women (mean age 33.5 years), being the most frequent locations for these findings. A PD signal was very rarely identified and exclusively on MTP joints.

Kitchen et al [22], by assessing multiple joints in healthy individuals, found US gray scale abnormalities (both synovial hypertrophy and effusion) in $88.4 \%$ of the 
$1^{\text {st }}$ MTP joint (the most common location for abnormal gray scale findings), mostly low grade, $28.3 \%$ having also PD signal (the second most common location for PD signal after the wrist). $1^{\text {st }}$ and $2^{\text {nd }}$ MTP joints were the only joints that had high grade gray scale findings also. A percentage of $37.9 \%$ of the $2^{\text {nd }}$ to $5^{\text {th }}$ MTP joints had gray scale findings (the third most common location after wrist for gray scale findings), mostly low grade, but had a much lower frequency of PD signal (3.7\%) compared with $1^{\text {st }}$ MTP and wrist. Overall gray scale findings, but not PD signal, positively correlated with age, probably due to synovial and capsular changes determined by osteoarthritis. PD signal, but not gray scale findings, positively correlated with serum vascular endothelial growth factor (VEGF) levels, probably linked to the synovial angiogenesis.

Padovano et al [23], who assessed by US 32 small joints (including MTP joints) in 207 healthy individuals, identified a higher prevalence of effusion, synovial hypertrophy or a PD signal at the level of the forefoot, than in the wrist or fingers. The most frequent US abnormalities were found in $1^{\text {st }}$ MTP $(36 \%)$, followed by $2^{\text {nd }}$ MTP $(30.5 \%), 3^{\text {rd }}$ MTP $(22 \%), 4^{\text {th }}$ MTP $(11 \%)$ and $5^{\text {th }}$ MTP $(0.5 \%)$. Grade 1 was the most frequent severity score detected with respect to effusion, synovial hypertrophy or PD signal. However, the $1^{\text {st }}$ and $2^{\text {nd }}$ MTP joints were the only joints with grade 3 synovial hypertrophy. PD signal was found most frequently in the $1^{\text {st }}$ MTP joint, this being the only joint where they found PD scores greater than 1 .

As we previously highlighted, grade 1 or low grade MTP synovial hypertrophy is frequently found in both healthy individuals and RA patients. Therefore, the clinical relevance of grade 1 synovial hypertrophy has been questioned. Witt et al [24] tried to answer this question and compared grade 1 synovial hypertrophy in wrist and small joints of the hands and feet of RA patients and healthy individuals. The overall conclusion of the study did not support the clinical relevance of grade 1 synovial hypertrophy, since most of the findings in both RA patients and healthy controls were grade 1 . Furthermore, no association with tenderness, swelling or PD signal could be done, and a poor response to therapy was observed. Regarding the MTP joints the authors found that grade 1 synovial hypertrophy was not different between RA patients with established disease and healthy controls but was significantly higher in patients with early RA when compared with healthy controls.

Hence, MTP joints should be routinely evaluated by US in patients with RA, even in the absence of clinical evidence of synovitis, since their involvement is predictive for further joint damage, deformities and impairment of foot functionality. However, it should not be forgotten that MTP joints abnormalities can be found in healthy individuals also, thus a good clinical algorithm is necessary to decide which US findings are due to RA.

\section{Erosions}

US is superior to radiography in the detection of bone erosions at the level of the MTP joint in patients with RA [25]. Skudlarek et al [12] found an agreement of $96 \%$ between US and MRI in identifying MTP erosions, with better results for US in the detection of erosions in the $1^{\text {st }}$ and $5^{\text {th }}$ MTP joints and in the detection of low-grade erosions (mentioning that the MRI performance is dependent on the MR slices thickness - 3-mm MR slices was used). Schmidt et al [11] used more thinner MR slices and identified more erosions using MRI than US. But, in daily practice, it has to be considered that US is a cheaper, repetitive, reproductible imaging technique and allows more rapid and multiple site assessment.

RA patients have significantly higher frequencies of MTP erosions compared to healthy individuals [14]. Patients with RA commonly develop foot erosions at the level of the plantar aspects of the metatarsal heads, most frequent in the $5^{\text {th }}$ MTP (easily assessed by radiography, US and MRI) even in the absence of hand erosions [2527].

Zayat et al [28] searched for erosions in multiple sites of the hands and feet of patients with RA, psoriatic arthritis (PsA), gout and healthy individuals, at the level of the foot focusing on $1^{\text {st }}$ and $5^{\text {th }}$ MTP. They found that erosions in RA patients are more frequent comparing with other groups but are not specific for RA [sensitivity (Se) 91.4\%, specificity (Sp) 32.9\%]. However, high grade erosions (more than grade 2) located in four sites, including the $5^{\text {th }}$ MTP, are highly specific for RA ( $\mathrm{Se} 41.4 \%$, Sp 97.9\%). $1^{\text {st }}$ MTP erosions were sensitive, but not specific for RA, while $5^{\text {th }}$ MTP joint erosions were highly specific and predictive for RA (more frequent in dorsal-lateral and plantar-lateral quadrants).

Bowen et al [29] also found that erosions of the MTP joint predominantly appear in the lateral half of the forefoot of the patients with RA.

Erosions at the level of $5^{\text {th }}$ MTP (namely the head of the $5^{\text {th }}$ metatarsal bone) can be identified from dorsal, lateral or plantar approaches of the $5^{\text {th }}$ MTP. Inanc et al [30] performed a study on 48 RA patients (mean age approximately 50 years old and mean disease duration of approximately 8 years) and tried to establish which approach is better in the detection of the $5^{\text {th }}$ MTP erosions. They detected $5^{\text {th }}$ MTP erosions in $69.8 \%$ of the examined feet, mostly in the plantar approach $(88 \%)$, followed by the lateral (79.1\%) and dorsal (22.4\%) approach. Similar results were found also in RA patients with disease duration less than 2 years. The frequency of plantar and 
lateral erosions in $5^{\text {th }}$ MTP were not statistically different, but both were significantly more frequent than those in dorsal approach. Also, $61.9 \%$ of the feet with erosions in one single approach had plantar erosions, significantly more frequent than the other approaches. Patients with erosions in the dorsal approach of the $5^{\text {th }}$ MTP had significantly higher disease duration than those with erosions only in lateral and plantar approach.

Corroborating these results, one might conclude that in RA patients foot erosions are most frequent and highly specific in the $5^{\text {th }}$ MTP. In this joint the erosions firstly appear in the plantar approach, followed by lateral and lastly by dorsal erosions.

\section{Bursae}

Within the plantar region of the forefoot, there are two types of bursae: intermetatarsal/anatomic bursae (real bursae between the interosseous tendons, that are lined with synovium) and submetatarsal/adventitial bursae (fluid filled areas located in the fat pad of the plantar aspect of the forefoot, non-real bursae). The intermetatarsal bursae are visible at US evaluation when pathologically inflamed as the accumulation of fluid (anechoic area that is compressible) surrounded by thickened, hypoechoic walls (due to the hypertrophy of the synovial layer), that bulges more than $1 \mathrm{~mm}$ under the metatarsal head level. The US examination of submetatarsal bursae shows a hypoechoic/anechoic or heterogenous fluid accumulations located at the level of submetatarsal fat tissue [6,31-35]. The intermetatarsal bursae are located just above the deep transverse metatarsal ligament, never extending below this structure. The neurovascular bundle are always located beneath this ligament, this anatomic relationship being very helpful in distinguishing bursitis from Morton's neuroma [35]. US is a very useful imaging technique to identify forefoot bursae, having a good inter-observer agreement [36].

In patients with RA intermetatarsal bursitis is more frequent than submetatarsal bursitis, the latter being mechanically produced [33]. The patients with RA have a higher prevalence of forefoot bursitis than healthy subjects, particularly between the fourth and the fifth intermetatarsal space [37]. Bowen et al [33] showed that the forefoot bursae suffer changes, both regression and progression, over a period of 12 months in patients with long standing RA, and their changes were associated with foot impairment and limitation of activity, but not with changes in disease activity. Similar results were obtained by Hooper et al [38] after 3-years follow-up, stating also that the presence of forefoot bursae is an independent predictor for foot impairment. In early RA patients with forefoot pain, Koski et al [32] identified a higher frequency of intermetatarsal bursitis than in healthy individuals, ap- proximately one quarter of these patients had no other US modification to justify the symptoms. Although the presence of PD signal usually signifies inflammation and activity, the value of its presence at the level of forefoot bursae is not yet established [39].

\section{Ultrasound findings of the ankle}

Three joints at the level of the ankle have particular significance in patients with RA: TT, talo-navicular (TN) and subtalar (ST). The ankle involvement in patients with RA appears in those with longer disease duration and higher disease activity score, as well as the bilateral involvement $[40,41]$.

The most frequent affected joints at the ankle and midfoot level in patients with RA are the TT and TN joint, respectively $[14,40,41]$, significantly more frequent in symptomatic ankle patients than in asymptomatic $(59 \%$ vs $35 \%$, and $35 \%$ vs $18 \%$ respectively) [41]. Unlike ST joint synovitis, TT and TN synovitis are positively associated with the disease activity [40].

When evaluating the PD signal of TT joint, its sensibility is lower in the anterior longitudinal scan of the ankle (due to the deep location of the synovium and the dorsalis pedis artery interposition), but the scan of medial and lateral aspect of the TT recess increases its sensibility [42]. The presence of a PD signal in the ST joint is better assessed from a posterolateral (parasagittal) scan given by the superficial localization of the synovium [42].

We performed a search in PubMed for published studies regarding ankle synovitis and tenosynovitis in patients with RA (search terms "Rheumatoid arthritis AND ankle AND ultraso* AND synovitis AND tenosynovitis", 18 studies founded). After the exclusion of reviews, papers with insufficient data about US parameters, papers related to therapy-induced changes or non-English language papers, we included in analysis 6 studies, detailed in Table I.

The first study that assessed ankle synovitis and tenosynovitis by US and MRI in patients with long-standing RA and a painful ankle, was performed in 1996 by Lehtinen et al [43]. They found high concordance of US with MRI, and poor concordance with clinical examination.

Suzuki et al [44] found that in symptomatic ankles of the patients with short-duration RA the most frequent US finding was tenosynovitis, predominantly of the medial compartment (46\%), followed by lateral $(29 \%)$ and anterior compartments $(10 \%)$. Joint synovitis was less frequent, the TT joint being the most affected (35\%), followed by the ST joint $(33 \%)$ and the TN joint $(27 \%)$. Also, they found that tenosynovitis appeared in patients 
Table I. Published studies regarding US-detectable ankle synovitis and tenosynovitis frequencies in patients with RA

\begin{tabular}{|c|c|c|c|c|c|c|}
\hline Study, year & $\begin{array}{l}\text { Number of pa- } \\
\text { tients (ankles) }\end{array}$ & Age (years) & $\begin{array}{l}\text { Disease duration } \\
\text { (years/months) }\end{array}$ & DAS-28* & Synovitis $^{\S}$ & Tenosynovitis $^{\S \S}$ \\
\hline Lehtinen [43] 1996 & $17(17)^{\#}$ & $51.5(27-72)^{*}$ & 9.5 y $(0.5-40)^{*}$ & N/A & $47 \%$ & $23.5 \%$ \\
\hline Suzuki [44] 2013 & $74(100)^{\#}$ & $63.3(26-83)^{*}$ & $4.2 \mathrm{mo}(0.23 \mathrm{mo}-19.4 \mathrm{y})^{*}$ & N/A & $56 \%$ & $61 \%$ \\
\hline Alsuwaidi [41] 2015 & $80(160)^{\# \#}$ & $60(28-81)^{*}$ & $5 \mathrm{y}(\text { range } 0-44)^{*}$ & $5.0(0.8-7.8)$ & $77 \%$ & $28 \%$ \\
\hline Gutierrez [45] 2016 & $216(432)^{\# \# \#}$ & $45.31 \pm 9.47^{* *}$ & $39.83 \mathrm{mo} \pm 21.98^{* *}$ & $3.59 \pm 0.76^{* *}$ & $12.73 \% ¥ ¥$ & $68.05 \%$ \\
\hline Toyota [46] 2016 & $60(120)$ & $60.9 \pm 15.2^{* *}$ & $6.98 \mathrm{y} \pm 7.96^{* *}$ & $3.93 \pm 1.63^{* * q}$ & $15.8 \%$ & $20.8 \%$ \\
\hline Elsaman [40] 2017 & $63(126)$ & $34(22-52)^{*}$ & $22 \mathrm{mo}(6-60)^{*}$ & $2.80(2.6-5.8)$ & $18.3 \%$ & $30.2 \%$ \\
\hline
\end{tabular}

${ }^{*}$ Data expressed as median (range); ${ }^{* *}$ Data expressed as mean \pm standard deviation; ${ }^{*}$ Only symptomatic ankles included; ${ }^{\#}$ Both symptomatic

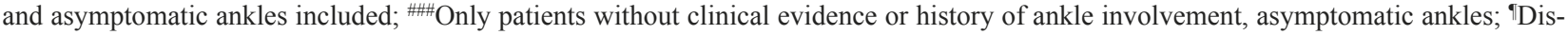
ease activity estimated by DAS28-ESR; ${ }^{\S}$ Overall (tibio-talar, talo-navicular, subtalar joints); ${ }^{\S}$ Overall (tibialis anterior, extensor hallucis longus, extensor digitorum, tibialis posterior, flexor digitorum, flexor hallucis longus, peroneus longus and brevis tendons; ${ }^{*}$ Subtalar joint not included; ${ }^{\sharp}$ Only tibio-talar joint assessed, without talonavicular and subtalar joints; $\mathrm{N} / \mathrm{A}=$ not available; $\mathrm{y}=$ years; $\mathrm{mo}=$ months

with significantly shorter disease duration $(11.4 \pm 21.6$ months), being more common in early RA $(<6$-months duration). Isolated tenosynovitis appeared in even shorter disease duration patients (5.9 \pm 8.7 months). Furthermore, in long-treated patients ( $>6$-months) joint synovitis was found more often, as opposed to isolated tenosynovitis found more often in short-treated patients.

Alsuwaidi et al [41] stated that the most frequent US findings in long-duration RA patients was synovitis of the TT and/or TN joints ( $49 \%$ and $28 \%$, respectively comparative with asymptomatic patients $35 \%$ and $18 \%$, respectively), followed by tenosynovitis of the medial compartment.

Gutierez et al [45] in a study on patients with RA and subclinical ankle involvement (asymptomatic patients without history or clinical evidence of ankle injury), identified US abnormalities at the level of the ankle in $87 \%$ of the patients, significantly more than in healthy individuals. The most frequently reported was tibialis posterior tenosynovitis (31.9\% of patients), followed by peroneus longus tenosynovitis and TT synovitis $(26.9 \%$ and $25 \%$ of patients, respectively), but they did not find a significant association between the US abnormalities and disease duration or disease activity.

The study of Totyota et al [46] provided similar data regarding the superiority of ankle tenosynovitis involvement (tibialis posterior tendon being the most affected) over the TT joint synovitis (as seen in Table I). They highlighted the superiority of US over clinical examination in identifying ankle involvement. Moreover, ankle US findings were among the independent predictors for the ankle pain.

Recently, Elsaman et al [40] observed that the most frequent US finding was tenosynovitis, followed by synovitis, erosions (8.7\%) and tendinosis (4\%). Also, they observed that the earliest US modification that appears in these patients is tenosynovitis, especially of the tibialis posterior, followed by synovitis, erosions, and lastly tendinosis. They also found that the most frequent tenosynovitis in patients with RA was tenosynovitis of the tibialis anterior $(22.2 \%)$, followed by tenosynovitis of the tibialis posterior $(20.6 \%)$, mentioning that tenosynovitis of the tibialis posterior appeared earliest in the disease evolution. Also, the presence of tenosynovitis was positively associated with the disease activity score.

Analyzing 142 patients with rheumatic inflammatory diseases (RA, SpA and gout) having swollen or painful ankle joints, Harman et al [47] observed that patients with RA had significantly more frequent tenosynovitis of the tibialis posterior and ST and TN joints synovitis, the last two especially in those with early RA. On the other hand, TT joint synovitis was found to be more common in patients with SpA and gout, but in RA it was found more frequently in patients with a disease duration more than 1 year. Also, ST joint synovitis, as well as tibialis posterior and peroneus tenosynovitis were found to be the best predictors for foot dysfunction in patients with RA. Similar negative impact of subclinical US-detectable foot and ankle synovitis on foot function and quality of life of the patients with RA is sustained by a recent study performed by Inamo et al [5].

An interesting conclusion derived from the aforementioned studies: tenosynovitis of the ankle tendons, especially of the tibialis posterior, characterizes the onset or early stage of RA, while ankle synovitis, mostly at the level of TT joint, characterizes the established, longstanding RA patients.

\section{Ultrasound changes of the heel}

By scanning the heel, the posterior recess of the TT joint, the ST joint and the entheses can be evaluated. At 
Table II. Heel entheses US-detectable modifications in patients with RA

\begin{tabular}{|c|c|c|c|c|c|c|c|c|c|}
\hline Study, year & $\begin{array}{l}\text { No of } \\
\text { patients } \\
\text { (heels) }\end{array}$ & $\begin{array}{l}\text { Disease } \\
\text { duration } \\
\text { (years) }\end{array}$ & DAS28 & Enthesis & Thickened & $\begin{array}{l}\text { Hypoecho- } \\
\text { genicity }\end{array}$ & $\begin{array}{l}\text { Entheso- } \\
\text { phytes }\end{array}$ & Erosions & Bursitis \\
\hline \multirow[t]{2}{*}{ Falsetti [50] 2003" } & 158 & $4(1.3-7.2)$ & N/A & AT & $2 \% *$ & $\mathrm{~N} / \mathrm{A}$ & $34 \%$ & $12 \%$ & $18 \%$ \\
\hline & & & & PF & $26 \% *$ & $\mathrm{~N} / \mathrm{A}$ & $46 \%$ & $6 \%$ & $10 \%^{* *}$ \\
\hline \multirow[t]{2}{*}{ Genc [53] 2005} & $24(48)$ & $7.21 \pm 4.54$ & N/A & AT & $41.6 \%$ & N/A & $10.4 \%$ & $6.25 \%$ & $18.75 \%$ \\
\hline & & & & FP & $4.16 \%$ & $\mathrm{~N} / \mathrm{A}$ & $16.6 \%$ & $4.16 \%$ & $\mathrm{~N} / \mathrm{A}$ \\
\hline Harman [54] 2017 & $27(54)$ & $7.29 \pm 5.83$ & $3.19 \pm 0.93$ & AT & $11.1 \%$ & N/A & $70.3 \% \S$ & $88.8 \%$ & $18.5 \%$ \\
\hline \multirow[t]{2}{*}{ Ebstein [48] 2018} & $30(60)$ & $10.5 \pm 7.9$ & $3.4 \pm 1.9$ & AT & $10 \%$ & $6.7 \%$ & $30 \%$ & $8.3 \%$ & N/A \\
\hline & & & & FP & $13.3 \%$ & $1.7 \%$ & $1.67 \%$ & $3.3 \%$ & N/A \\
\hline
\end{tabular}

Percentages calculated related to the number of US-examined heels; \#Percentages calculated related to the number of subjects having the US modification; "Data available for Achilles tendon enthesitis and plantar fasciitis, respectively, no data available for thickness and hypoechogenicity; ${ }^{* *}$ Data presented for subcalcaneal panniculitis; ${ }^{\circledR}$ Data reported as "posterior pole of calcaneus enthesis calcification", not as enthesophytes; $\mathrm{AT}=$ Achilles tendon; $\mathrm{PF}=$ plantar fascia

the level of the heel, there are two important sites (entheses) to be assessed: Achilles tendon with its peritendinous structures (paratenon and deep and superficial retrocalcanean bursa) and plantar fascia (plantar aponeurosis), as well as the adjacent cortical surface of the calcaneum $[48,49]$. Another concept was additionally described at the level of the inferior heel: subcalcaneal panniculitis, defined as inflammatory or degenerative modification of the heel pad which loses its lobular structure and becomes intense hypoechogenic, inhomogeneous, thickened, and compressible [50-52].

The heel enthesis inflammatory pathology is typically related to SpA but there are published studies about the presence of US abnormalities at the level of Achille's tendon and plantar fascia in RA patients (detailed in Table II).

Falsetti et al [50], in a study performed on patients with osteoarthritis, RA, PsA and healthy individuals, found that Achilles enthesitis and posteroinferior (Achilles) enthesophytes were significantly more frequent in patients with PsA than RA ( $8 \%$ vs. $2 \%, 49 \%$ vs $34 \%$, respectively). On the contrary, RA patients had significantly higher frequency of deep retrocalcaneal bursitis $(18 \%$ vs $6 \%)$, posterior and inferior calcaneal erosions ( $12 \%$ vs $5 \%, 6 \%$ vs $1 \%$, respectively) and subcalcaneal panniculitis $(10 \%$ vs $1 \%)$. No difference was found regarding inferior (plantar fascia) enthesophytes and plantar fasciitis. In healthy individuals only posteroinferior and inferior enthesophytes were found, both being significantly less frequent than in RA and PsA patients.

Genc et al [53] performed a study on RA, ankylosing spondylitis (AS) patients and healthy individuals, stating that there is no significant difference in the frequency of Achilles enthesitis and plantar fasciitis in RA and AS patients. When compared to healthy individuals, Achilles enthesitis had higher frequencies in RA and AS patients with similar plantar fasciitis frequencies in all three groups. No other statistical analysis results were published in this article regarding the differences between the groups of the other US parameters considering Achilles enthesis and plantar fascia, only raw data being available.

Harman et al [54] found that the increase in thickness of Achille's paratenon in RA patients, unlike those with axial $\mathrm{SpA}$, is independently associated with disease activity.

Ebstein et al [48], based on a study performed on RA and $\mathrm{SpA}$ patients, and healthy individuals, observed that there was no difference in the frequency of painful entheses at clinical examination and US-detectable abnormalities at the level of Achilles tendon and plantar fascia between patients with RA and SpA. They found significant higher frequencies of these US modifications when compared to healthy individuals.

\section{Conclusions}

The foot and ankle in RA patients should be carefully assessed and for that purpose US can provide significant information that can influence the clinical judgment and therapeutic decision. At the level of the forefoot special attention should be given to the $5^{\text {th }}$ MTP joint regarding synovitis and erosions, especially in the plantar aspect of the joint. At the level of the ankle, in early RA, tenosynovitis is more likely to be found and in long standing RA ankle synovitis. Also, the heel evaluation can bring supplementary findings that can explain the symptoms of RA patients.

\section{Conflicts of interest: none}

\section{References}

1. Kapral T, Dernoschnig F, Machold KP, et al. Remission by composite scores in rheumatoid arthritis: are ankles and feet important? Arthritis Res Ther 2007;9:R72. 
2. Wechalekar MD, Lester S, Hill CL, et al. Active Foot Synovitis in Patients With Rheumatoid Arthritis: Unstable Remission Status, Radiographic Progression, and Worse Functional Outcomes in Patients With Foot Synovitis in Apparent Remission. Arthritis Care Res (Hoboken) 2016;68:1616-1623.

3. van der Leeden M, Steultjens M, Dekker JH, Prins AP, Dekker J. Forefoot joint damage, pain and disability in rheumatoid arthritis patients with foot complaints: the role of plantar pressure and gait characteristics. Rheumatology 2006;45:465-469.

4. Stolt M, Suhonen R, Leino-Kilpi H. Foot health in patients with rheumatoid arthritis-a scoping review. Rheumatol Int 2017;37:1413-1422.

5. Inamo J, Kaneko Y, Sakata K, Takeuchi T. Impact of subclinical synovitis in ankles and feet detected by ultrasonography in patients with rheumatoid arthritis. Int J Rheum Dis 2019;22:62-67.

6. Bowen CJ, Edwards CJ, Hooper L, et al. Improvement in symptoms and signs in the forefoot of patients with rheumatoid arthritis treated with anti-TNF therapy. J Foot Ankle Res 2010;3:10.

7. Cheung PP, Mari K, Devauchelle-Pensec V, et al. Predictive value of tender joints compared to synovitis for structural damage in rheumatoid arthritis. RMD Open 2016;2:e00205.

8. Funck-Brentano T, Gandjbakhch F, Etchepare F, et al. Prediction of radiographic damage in early arthritis by sonographic erosions and power Doppler signal: a longitudinal observational study. Arthritis Care Res (Hoboken) 2013;65:896-902.

9. Ten Cate DF, Luime JJ, Swen N, et al. Role of ultrasonography in diagnosing early rheumatoid arthritis and remission of rheumatoid arthritis--a systematic review of the literature. Arthritis Res Ther 2013;15:R4.

10. Rezaei H, Torp-Pedersen S, af Klint E, et al. Diagnostic utility of musculoskeletal ultrasound in patients with suspected arthritis - a probabilistic approach. Arthritis Res Ther 2014;16:448.

11. Schmidt WA, Schicke B, Ostendorf B, Scherer A, Krause A, Walther M. Low-field MRI versus ultrasound: which is more sensitive in detecting inflammation and bone damage in MCP and MTP joints in mild or moderate rheumatoid arthritis? Clin Exp Rheumatol 2013;31:91-96.

12. Szkudlarek M, Narvestad E, Klarlund M, Court-Payen M, Thomsen HS, Ostergaard M. Ultrasonography of the metatarsophalangeal joints in rheumatoid arthritis: comparison with magnetic resonance imaging, conventional radiography, and clinical examination. Arthritis Rheum 2004;50:2103-2112.

13. Le Boedec M, Jousse-Joulin S, Ferlet JF, et al. Factors influencing concordance between clinical and ultrasound findings in rheumatoid arthritis. The J Rheumatol 2013;40:244-252.

14. Sant'Ana Petterle G, Natour J, Rodrigues da Luz K, et al. Usefulness of US to show subclinical joint abnormalities in asymptomatic feet of RA patients compared to healthy controls. Clin Exp Rheumatol 2013;31:904-912.
15. Scire CA, Iagnocco A, Meenagh G, et al. Ultrasound imaging for the rheumatologist XXXIII. Sonographic assessment of the foot in early arthritis patients. Clin Exp Rheumatol 2011;29:465-469.

16. Ozer PK, Sahin O, Ozer Z, Cengiz AK, Durmaz Y, Kaptanoglu E. Ultrasound-defined remission for good functional status in rheumatoid arthritis. Indian J Med Res 2017; 146:230-236.

17. Hiraga M, Ikeda K, Shigeta K, et al. Sonographic measurements of low-echoic synovial area in the dorsal aspect of metatarsophalangeal joints in healthy subjects. Mod Rheumatol 2015;25:386-392.

18. Keen HI, Redmond A, Wakefield RJ, et al. An ultrasonographic study of metatarsophalangeal joint pain: synovitis, structural pathology and their relationship to symptoms and function. Ann Rheum Dis 2011;70:2140-2143.

19. Luukkainen R, Ekman P, Luukkainen P, Koski JM. Ultrasonographic findings in metatarsophalangeal and talocrural joints in healthy persons. Clin Rheum 2009;28:311-313.

20. Machado FS, Natour J, Takahashi RD, de Buosi AL, Furtado RN. Sonographic assessment of healthy peripheral joints: evaluation according to demographic parameters. J Ultrasound Med 2014;33:2087-2098.

21. Micu MC, Fodor D, Micu R, Bolboaca SD, Ionescu R. Pregnant versus non-pregnant healthy subjects - a prospective longitudinal musculoskeletal ultrasound study concerning the spectrum of normality. Med Ultrason 2018;20:319-327.

22. Kitchen J, Kane D. Greyscale and power Doppler ultrasonographic evaluation of normal synovial joints: correlation with pro- and anti-inflammatory cytokines and angiogenic factors. Rheumatology 2015;54:458-462.

23. Padovano I, Costantino F, Breban M, D'Agostino MA. Prevalence of ultrasound synovial inflammatory findings in healthy subjects. Annals of the rheumatic diseases. 2016;75:1819-23.

24. Witt M, Mueller F, Nigg A, Reindl C, Leipe J, Proft F, et al. Relevance of grade 1 gray-scale ultrasound findings in wrists and small joints to the assessment of subclinical synovitis in rheumatoid arthritis. Ann Rheum Dis 2013;65:1694-1701.

25. Lopez-Ben R, Bernreuter WK, Moreland LW, Alarcon GS. Ultrasound detection of bone erosions in rheumatoid arthritis: a comparison to routine radiographs of the hands and feet. Skeletal Radiol 2004;33:80-84.

26. Grassi W, Filippucci E, Farina A, Salaffi F, Cervini C. Ultrasonography in the evaluation of bone erosions. Ann Rheum Dis 2001;60:98-103.

27. Siddle HJ, Hensor EM, Hodgson RJ, et al. Anatomical location of erosions at the metatarsophalangeal joints in patients with rheumatoid arthritis. Rheumatology 2014;53:932-936.

28. Zayat AS, Ellegaard K, Conaghan PG, et al. The specificity of ultrasound-detected bone erosions for rheumatoid arthritis. Ann Rheum Dis 2015;74:897-903.

29. Bowen CJ, Culliford D, Allen R, et al. Forefoot pathology in rheumatoid arthritis identified with ultrasound may not localise to areas of highest pressure: cohort observations at baseline and twelve months. J Foot Ankle Res. 2011;4:25. 
30. Inanc N, Ozen G, Aydin SZ, Kasapoglu-Gunal E, Direskeneli H. Ultrasonographic Assessment of Fifth Metatarsophalangeal Joint Erosion in Rheumatoid Arthritis: Which Aspect Is Better? Ultrasound Med Biol 2016;42:864869.

31. Iagnocco A, Coari G, Palombi G, Valesini G. Sonography in the study of metatarsalgia. The J Rheumatol 2001;28:13381340.

32. Koski JM. Ultrasound detection of plantar bursitis of the forefoot in patients with early rheumatoid arthritis. J Rheumatol 1998;25:229-230.

33. Bowen CJ, Hooper L, Culliford D, et al. Assessment of the natural history of forefoot bursae using ultrasonography in patients with rheumatoid arthritis: a twelve-month investigation. Arthritis Care Res (Hoboken) 2010;62:17561762.

34. Studler U, Mengiardi B, Bode B, et al. Fibrosis and adventitious bursae in plantar fat pad of forefoot: MR imaging findings in asymptomatic volunteers and MR imaging-histologic comparison. Radiology 2008;246:863-870.

35. Theumann NH, Pfirrmann CW, Chung CB, et al. Intermetatarsal spaces: analysis with MR bursography, anatomic correlation, and histopathology in cadavers. Radiology 2001;221:478-484.

36. Bowen CJ, Dewbury K, Sampson M, et al. Musculoskeletal ultrasound imaging of the plantar forefoot in patients with rheumatoid arthritis: inter-observer agreement between a podiatrist and a radiologist. J Foot Ankle Res 2008;1:5.

37. Bowen CJ, Culliford D, Dewbury K, et al. The clinical importance of ultrasound detectable forefoot bursae in rheumatoid arthritis. Rheumatology (Oxford) 2010;49:191192.

38. Hooper L, Bowen CJ, Gates L, et al. Prognostic indicators of foot-related disability in patients with rheumatoid arthritis: results of a prospective three-year study. Arthritis Care Res (Hoboken) 2012;64:1116-1124.

39. Endo Y, Koga T, Eguchi M, et al. Utility of power Doppler ultrasonography for detecting forefoot bursae in early rheumatoid arthritis: A case report. Medicine (Baltimore) 2018;97:e13295.

40. Elsaman AM, Mostafa ES, Radwan AR. Ankle Evaluation in Active Rheumatoid Arthritis by Ultrasound: A CrossSectional Study. Ultrasound Med Biol 2017;43:2806-2813.

41. Alsuwaidi M, Ehrenstein B, Fleck M, Hartung W. Asymptomatic Versus Symptomatic Ankle Joints in Rheumatoid Arthritis: A High-Resolution B-Mode and Power Doppler Ultrasound Study. Arthritis Care Res (Hoboken 2016;68:861-864.
42. Suzuki T. Power Doppler ultrasonographic assessment of the ankle in patients with inflammatory rheumatic diseases. World J Orthop 2014;5:574-584.

43. Lehtinen A, Paimela L, Kreula J, Leirisalo-Repo M, Taavitsainen M. Painful ankle region in rheumatoid arthritis. Analysis of soft-tissue changes with ultrasonography and MR imaging. Acta Radiol 1996;37:572-577.

44. Suzuki T, Okamoto A. Ultrasound examination of symptomatic ankles in shorter-duration rheumatoid arthritis patients often reveals tenosynovitis. Clin Exp Rheumatol 2013;31:281-284.

45. Gutierrez M, Pineda C, Salaffi F, et al. Is ankle involvement underestimated in rheumatoid arthritis? Results of a multicenter ultrasound study. Clin Rheumatol 2016;35:26692678.

46. Toyota Y, Tamura M, Kirino Y, et al. Musculoskeletal ultrasonography delineates ankle symptoms in rheumatoid arthritis. Mod Rheumatol 2017;27:425-429.

47. Harman H, Tekeoglu I. Ankle pathologies in patients with inflammatory rheumatic diseases: a clinical and ultrasonographic study. Int J Rheum Dis 2017;20:675-684.

48. Ebstein E, Coustet B, Masson-Behar V, et al. Enthesopathy in rheumatoid arthritis and spondyloarthritis: An ultrasound study. Joint Bone Spine 2018;85:577-581.

49. Terslev L, Naredo E, Iagnocco A, et al. Defining enthesitis in spondyloarthritis by ultrasound: results of a Delphi process and of a reliability reading exercise. Arthritis Care Res 2014;66:741-748.

50. Falsetti P, Frediani B, Fioravanti A, et al. Sonographic study of calcaneal entheses in erosive osteoarthritis, nodal osteoarthritis, rheumatoid arthritis and psoriatic arthritis. Scand J Rheumatol 2003;32:229-234.

51. Falsetti P, Frediani B, Acciai C, et al. Ultrasonography and magnetic resonance imaging of heel fat pad inflammatoryoedematous lesions in rheumatoid arthritis. Scand J Rheumatol 2006;35:454-458.

52. Falsetti P, Frediani B, Acciai C, Baldi F, Filippou G, Marcolongo R. Heel fat pad involvement in rheumatoid arthritis and in spondyloarthropathies: an ultrasonographic study. Scand J Rheumatol 2004;33:327-331.

53. Genc H, Cakit BD, Tuncbilek I, Erdem HR. Ultrasonographic evaluation of tendons and enthesal sites in rheumatoid arthritis: comparison with ankylosing spondylitis and healthy subjects. Clin Rheumatol 2005;24:272-277.

54. Harman H, Suleyman E. Features of the Achilles tendon, paratenon, and enthesis in inflammatory rheumatic diseases : A clinical and ultrasonographic study. Z Rheumatol 2018;77:511-521. 